\title{
Highly Sensitive Thin Film Sensor Using Coplanar Line
}

\author{
H. Uetake, S. Yabukami, T. Chiba, T. Ozawa, H. Suzuki, N. Kobayashi*, and K.I. Arai* \\ Tohoku Gakuin University, 1-13-1 Chuo, Tagajo 985-8537, Japan \\ *Research Institute for Electric and Magnetic Materials, 2-1-1 Yagiyama-minami, Taihaku-ku, Sendai 982-0807, Japan
}

A very sensitive thin film sensor was developed using a transmission line. The sensor element consisted of a coplanar line fabricated from $\mathrm{Sr}_{33} \mathrm{Ti}_{16} \mathrm{O}_{51}$ (STO) film $(6 \mu \mathrm{m}$ thick), amorphous CoNbZr film $(5 \mu \mathrm{m}$ thick), and $\mathrm{Cu} / \mathrm{Cr}$ film $(4 \mu \mathrm{m} / 0.2$ $\mu \mathrm{m})$. The deposited STO film had high permittivity of around 31. The STO film enhanced the sensitivity of the sensor and a phase change of more than 100 degrees/Oe and gain of over $-40 \mathrm{~dB}$ were achieved simultaneously. These characteristics are very similar to those of a large sensor with a bulky ceramic substrate ${ }^{6}$.

Key words: coplanar line, thin film sensor, $\mathrm{Sr}_{33} \mathrm{Ti}_{16} \mathrm{O}_{51}$ film

\section{Introduction}

Biomagnetic measurement such as magnetocardiography (MCG) and magneto encephalography (MEG) is applied by SQUID $^{12)}$ or laser-pumped magnetometer ${ }^{3)}$. However, these sensors are very expensive and not easily operated. On the other hand, an induction coil ${ }^{4)}$ and a fluxgate sensor $^{5)}$ can be operated at room temperature; however, they are comparatively large in scale, making it difficult to integrate them in a sensor array. Highly sensitive magnetic field thin film sensors operating at room temperature are useful for biomedical applications or nondestructive evaluation. Thus, development of a thin film sensor to measure biomagnetic signals at room temperature was the aim of this study.

As previously reported, a coplanar line-type thin film sensor with a ceramic substrate $\left(\varepsilon_{\mathrm{r}}=115\right)$ to enhance sensitivity of phase change was developed $\left.{ }^{6}\right)$ and successfully used to obtain magnetocardiograms (MCGs) at multiple points ${ }^{7}$. The ceramic substrate with high permittivity decreases the wave length of the carrier, the phase dramatically changing when a small field is applied. However the sensor is bulky and cannot be integrated.

In the present study, we developed a thin film integrated sensor including magnetic thin film, dielectric film and conductive film. These structure can be easily developed for array sensors with the same characteristics. The goal of this study was to obtain a sensor with good characteristics (phase change $>100$ degree/Oe, gain $>-40 \mathrm{~dB}$ ) for obtaining magnetocardiograms ${ }^{7)}$.

\section{Experimental procedure}

\subsection{Coplanar line-type thin film sensor}

Fig. 1 shows the structure of a coplanar line-type sensor. The sensor element consists of a coplanar line (19.8 $\mathrm{mm}$ in length, $0.3 \mathrm{~mm}$ in width, $4 \mu \mathrm{m}$ in thickness, and having a $0.05 \mathrm{~mm}$ gap between conductors), $\mathrm{Sr}_{33} \mathrm{Ti}_{16} \mathrm{O}_{51}$ (STO) film (6 $\mu \mathrm{m}$ in thickness), and an amorphous CoNbZr film (18.2 mm $\mathrm{x} 1.15 \mathrm{~mm}, 5 \mu \mathrm{m}$ in thickness), as shown in Fig. 1. The coplanar structure was fabricated by the lift-off process. The sputtering conditions are shown in Table 1. Amorphous CoNbZr film was deposited by RF sputtering on a glass substrate $(25 \mathrm{~mm} \times 25 \mathrm{~mm}, 1 \mathrm{~mm}$ in thickness). In order to induce transverse magnetic anisotropy of a few Oe, a DC field of $0.3 \mathrm{~T}$ was applied during annealing after film deposition. Rotational annealing was carried out at $400{ }^{\circ} \mathrm{C}$ for 2 hours, and then static annealing was conducted at $300{ }^{\circ} \mathrm{C}$ for 1 hour. The STO film was deposited by $\mathrm{RF}$ sputtering and annealed at $150{ }^{\circ} \mathrm{C}$ during deposition. We selected STO film as dielectric film

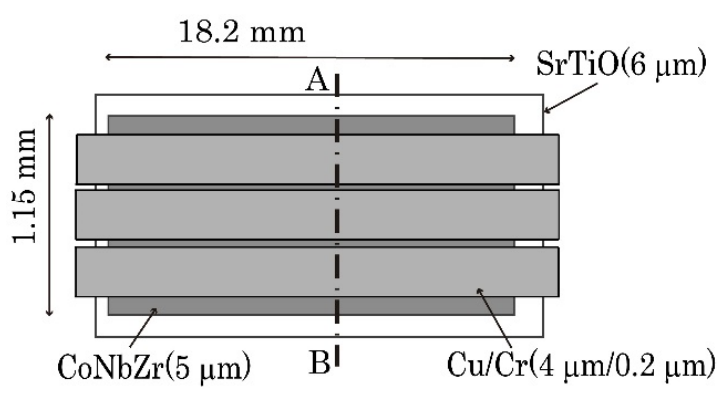

(a) Top view

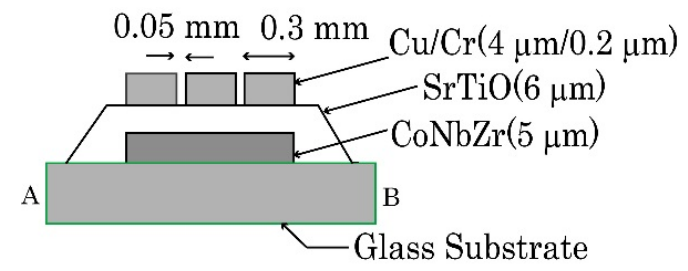

(b) Cross-sectional view

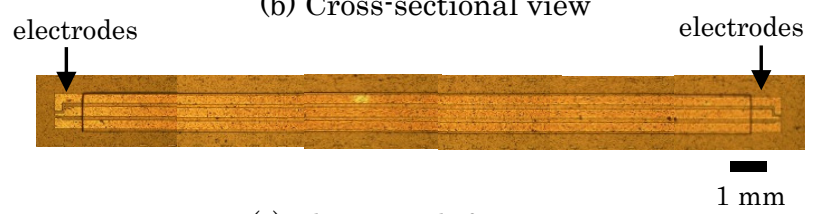

(c) Photograph from top

Fig. 1 Schematic of sensor. 
Table 1 Sputtering conditions.

\begin{tabular}{c|ccc}
\hline \hline & $\mathrm{CoNbZr}$ & $\mathrm{Sr}_{33} \mathrm{Ti}_{16} \mathrm{O}_{51}$ & $\mathrm{Cu} / \mathrm{Cr}$ \\
\hline Power, & $200 \mathrm{~W}$ & $200 \mathrm{~W}$ & $200 \mathrm{~W}$ \\
pressure & 20 mtorr & 20 mtorr & 20 mtorr \\
\hline time & 8 hour & 12 hour & 50 minutes \\
\hline thickness & $5 \mu \mathrm{m}$ & $6 \mu \mathrm{m}$ & $4 \mu \mathrm{m} / 0.2 \mu \mathrm{m}$ \\
\hline \hline
\end{tabular}

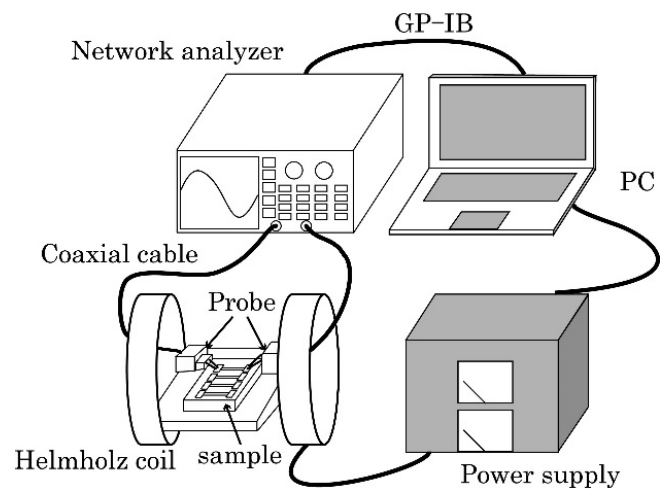

Fig. 2 Measurement setup.

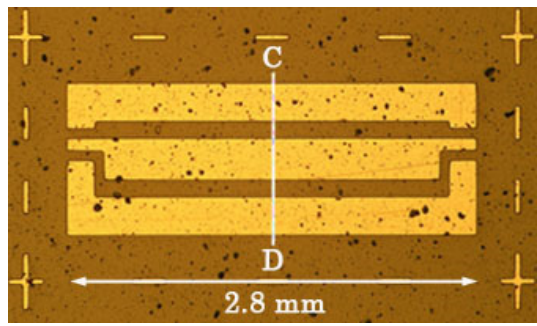

Fig. 3 Photograph of coplanar line (sample A) for a measurement of permittivity of STO film.

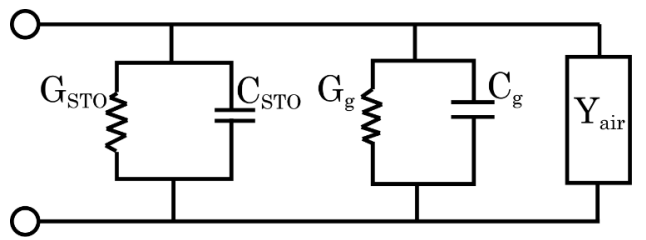

Fig. 4 Equivalent circuit of coplanar line in open terminated.

of the coplanar line, because STO film keeps high permittivity and low loss up to $\mathrm{GHz}$ range. The composition of the STO film was evaluated by X-ray photoelectron spectroscopy (JEOL JPS-9010MC). The composition of the STO film was obtained about $\mathrm{Sr}_{33} \mathrm{Ti}_{16} \mathrm{O}_{51} . \mathrm{Cu}$ and $\mathrm{Cr}$ film was deposited by RF sputtering. $\mathrm{Cr}$ film improves the contact between STO film and $\mathrm{Cu}$ film. The coplanar line was patterned using a lift-off. A carrier of around $2 \mathrm{GHz}$ flows in the center conductor of the coplanar line. When a small magnetic field is applied to the magnetic film, permeability of the magnetic film changes, which results in the amplitude and the phase of the carrier being changed due to the skin effect and ferromagnetic resonance. The carrier current flows in the $\mathrm{Cu}$ conductor, not in the $\mathrm{CoNbZr}$ film, so the sensor is different from conventional GMI

\begin{tabular}{|c|c|}
\hline \multicolumn{2}{|c|}{$\begin{array}{l}\text { Prepare coplanar line (main sample with STO } \\
\text { film, reference sample without STO film) }\end{array}$} \\
\hline $\begin{array}{l}\text { Measure capacitance (susceptance) } \\
\text { conductance of coplanar line in open } \\
G_{\text {main }}+j \omega C_{\text {main }} \text { (main sample with } \mathrm{S} \\
+j \omega C_{\text {ref }} \text { (reference sample without } \mathrm{S}\end{array}$ & $\begin{array}{l}\text { ited, } \\
\text { Tref }\end{array}$ \\
\hline $\begin{array}{l}\text { Obtain capacitance and conductance } \\
\text { film, } C_{\mathrm{STO}}=C_{\text {main }}-C_{\text {ref }}, G_{\mathrm{STO}}=G_{\text {mair }}\end{array}$ & \\
\hline $\begin{array}{l}\text { Calculate capacitance, } C_{\text {cal }}\left(\varepsilon_{\mathrm{r}}\right) \text {, of cop } \\
\text { as a function of } \varepsilon_{\mathrm{r}} \text { by FEM analysis i }\end{array}$ & $\begin{array}{l}\text { line } \\
7\end{array}$ \\
\hline $\begin{array}{l}\text { Optimize static permittivity }\left(\varepsilon_{\mathrm{r}}\right) \text { of } \mathrm{S} \\
\text { eq. (1) } \\
\mathrm{C}_{\mathrm{STO}}\left(=\mathrm{C}_{\text {main }}-\mathrm{C}_{\text {ref }}\right)=\mathrm{C}_{\text {cal }}\left(\varepsilon_{\mathrm{r}}\right)-\mathrm{C}_{\text {cal }}\left(\varepsilon_{\mathrm{r}}\right.\end{array}$ & $\begin{array}{r}\mathrm{m} \text { by } \\
\text { (1) }\end{array}$ \\
\hline $\begin{array}{l}\text { Obtain } \varepsilon_{\mathrm{r}}{ }^{+}+j \varepsilon_{\mathrm{r}} ” \\
\qquad \varepsilon_{r}{ }^{\prime}=C_{c a l}{ }^{-1}\left(C_{\text {main }}-C_{r e f}\right) \\
\varepsilon_{r}{ }^{\prime \prime}=\varepsilon_{r}{ }^{\prime} \frac{G_{\text {main }}-G_{r e f}}{j \omega\left(C_{\text {main }}-C_{r e f}\right)}\end{array}$ & $\begin{array}{l}(2) \\
(3)\end{array}$ \\
\hline
\end{tabular}

Fig. 5 Flow chart of an evaluation of permittivity of STO film.

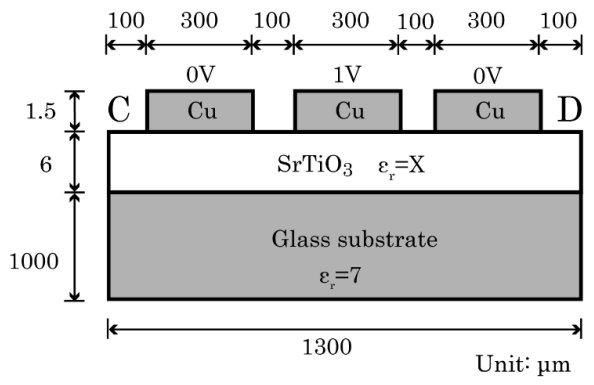

Fig. 6 Calculation model of coplanar line (sample A).

sensors in this respect. A magnetic field was applied in the longitudinal direction of the coplanar pattern by a Helmholtz coil. A conventional wafer probe (GSG-40-150) was put into contact with the sensor. The transmission coefficient $\left(S_{21}\right)$ was measured by network analyzer (HP8752A) when the magnetic field was slowly changed as shown in Fig. 2. The frequency span was $300 \mathrm{kHz}-3$ $\mathrm{GHz}$, the bandwidth was $3 \mathrm{kHz}$ and averaging was done 16 times in the network analyzer.

\subsection{Permittivity of STO film}

Fig. 3 shows a coplanar line for an evaluation of permittivity of STO film. The STO film thickness was 6 $\mu \mathrm{m}$, which was the same as the sensor in Fig. 1. The length of the coplanar line was $2.8 \mathrm{~mm}$, being free from wave length resonance up to $3 \mathrm{GHz}$. Fig. 4 shows an equivalent circuit of the coplanar line in open terminated. Fig. 5 shows a flow chart of an evaluation of permittivity 


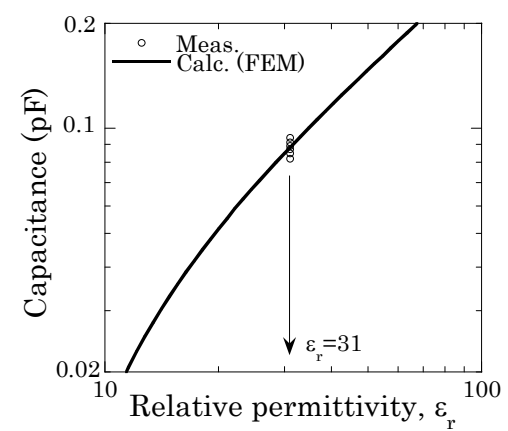

Fig. 7 Relation between capacitance of coplanar line and relative permittivity of STO film.

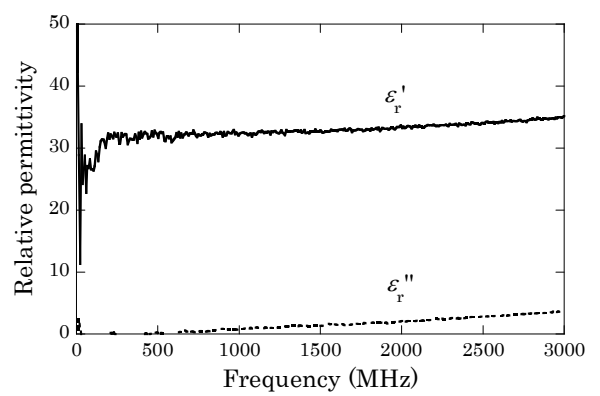

Fig. 8 Measured permittivity of the STO film as a function of frequency.

of STO film. Firstly coplanar line with STO film (main sample) was fabricated as shown in Fig. 3. Another coplanar line (reference sample) was deposited directly on the glass substrate without STO film as a reference. In Fig. $4, G_{\mathrm{STO}}$ is conductance of STO film, $C_{\mathrm{STO}}$ is capacitance of STO film, $G_{\mathrm{g}}$ is conductance of glass substrate, $C_{\mathrm{g}}$ is capacitance of glass substrate, and $Y_{\text {air }}$ is stray admittance. The capacitance (susceptance) and the conductance was obtained by reflection coefficient $\left(S_{11}\right)$ when the coplanar line was open circuited. Then the capacitance, $C_{\text {main }}-C_{\text {ref }}$, and conductance, $G_{\text {main }}-$ $G_{\text {ref }}$ were obtained as a contribution of the STO film. Fig. 6 shows the electric field calculation model and a crosssectional view of the STO film and $\mathrm{Cu}$ film on a glass substrate. The STO film and $\mathrm{Cu}$ film was the same thickness as the coplanar line in Fig. 3. Input voltage of $1 \mathrm{~V}$ and $0 \mathrm{~V}$ were applied to the center conductor and outer conductors (ground plane) respectively. The DC electric field distribution and capacitance were calculated using FEM analysis (Ansoft Maxwell 2D). The permittivity of the STO film was changed from 7 to 300 as a parameter, and that of the glass substrate was 7 . The calculated capacitance, $C_{\text {cal }}\left(\varepsilon_{\mathrm{r}}\right)$, was obtained from the integral of the electric field distribution. Then the capacitance, $\mathrm{C}_{\text {cal }}\left(\varepsilon_{\mathrm{r}}\right)-\mathrm{C}_{\mathrm{cal}}\left(\varepsilon_{\mathrm{r}}=7\right)$ were obtained as a contribution of STO film. Static permittivity of STO film was optimized by equation (1) in Fig. 5. Fig. 7 shows the capacitance of the coplanar line as a function of the static permittivity of STO film. Measured capacitances (six samples), $C_{\text {main }}-C_{\text {ref }}$, were obtained around $0.09 \mathrm{pF}$,

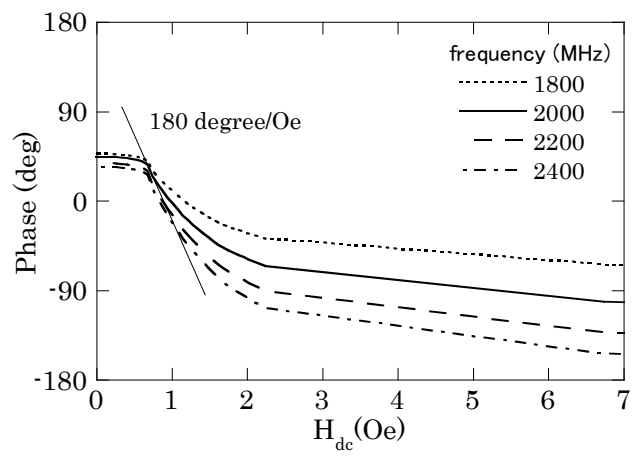

(a) Dependence on magnetic field

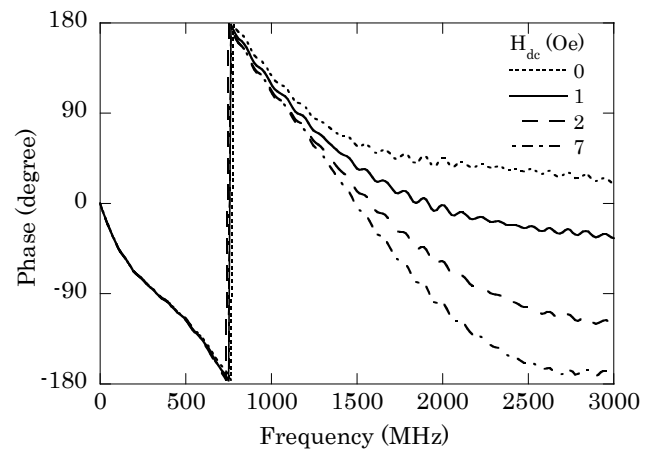

(b) Dependence on frequency

Fig. 9 Phase change of sensor output.

therefore effective static relative permittivity was optimized about 31 . Fig. 8 shows a complex permittivity of STO film. Real part of relative permittivity, $\varepsilon_{\mathrm{r}}^{\text {, }}$, was inversely obtained equation (2) of Fig. 5, imaginary part, $\varepsilon_{\mathrm{r}}$, was obtained equation (3) of Fig. 5. $\varepsilon_{\mathrm{r}}^{\prime}$ was almost constant, $\varepsilon_{\mathrm{r}}$ " was quite smaller than $\varepsilon_{\mathrm{r}}$ ' up to $3 \mathrm{GHz}$. The dissipation factor, $\tan \delta$, was obtained about 0.06 at 2 $\mathrm{GHz}$.

\section{Experimental Results}

\subsection{Phase change of the sensor}

Fig. 9 shows the phase of transmission coefficient $\left(S_{21}\right)$. Fig. 9 (a) shows the phase as a function of magnetic field, and (b) shows the phase as a function of the carrier frequency. Maximum phase change around 180 degree/Oe was obtained around $2.2 \mathrm{GHz}$ and $0.8 \mathrm{Oe}$. In Fig. 9(b), the phase change increased as the frequency increased because the phase constant of the coplanar line increased as the frequency increased. Fig. 10 shows a gain of transmission coefficient $\left(S_{21}\right)$. Fig. 10(a) shows the gain as a function of the applied field, and (b) shows the gain as a function of the carrier frequency. The gain decreased as the frequency increased because the loss of CoNbZr film and $\mathrm{Cu}$ film increased. The gain was obtained over $-40 \mathrm{~dB}$ under $2.2 \mathrm{GHz}$, which is suitable for the application of magnetocardiography ${ }^{7}$. Therefore, the sensor obtained both high phase change of 180 


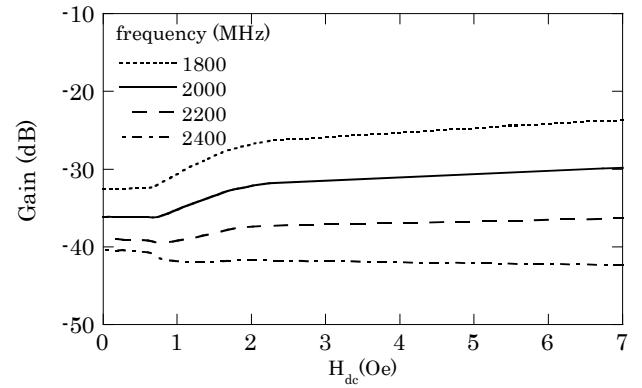

(a) Dependence on magnetic field

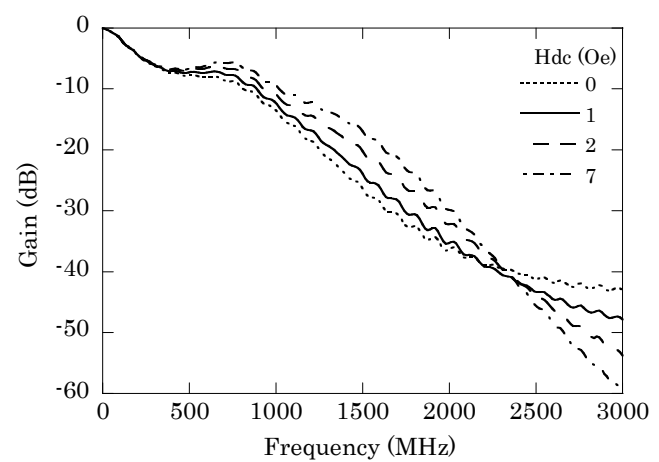

(b) Dependence on frequency

Fig. 10 Amplitude of sensor output.

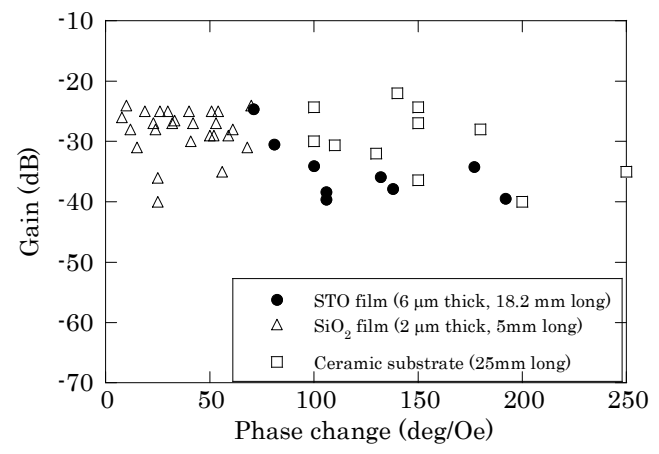

Fig. 11 Phase change and gain of sensors.

degree/Oe and gain within $-40 \mathrm{~dB}$ simultaneously.

Fig. 11 shows the phase change and gain when dielectric materials were STO film, $\mathrm{SiO}_{2}$ film, or ceramic substrate. The sensor with $\mathrm{SiO}_{2}$ film ( $2 \mu \mathrm{m}$ in thickness) was fabricated with the same structure as that shown in Fig. 1, although the sensor length was $5 \mathrm{~mm}$. The sensor with a ceramic substrate ( $50 \mathrm{~mm}$ x $50 \mathrm{~mm}, 0.5 \mathrm{~mm}$ in thickness, $\varepsilon_{\mathrm{r}}=115$ ) was combined with large CoNbZr film $(25 \mathrm{~mm} \times 25 \mathrm{~mm})^{6}$. The sensor using STO film improved sensitivity by over 100 degree/Oe compared with the sensor using $\mathrm{SiO}_{2}$ film because high permittivity of STO film improved sensitivity. Both sensors with STO film and the ceramic substrate had good sensitivity over 100 degree/Oe because both material has high permittivity. The gain of the sensor using STO film was slightly lower than that of the sensor using the ceramic substrate, which was because the $\mathrm{Cu}$ thickness $(4 \mu \mathrm{m})$ of the sensor using STO film was thinner than the thickness of the $\mathrm{Cu}(18 \mu \mathrm{m})$ using the ceramic substrate.

\section{Conclusions}

1. A coplanar line-type thin film sensor composed of $\mathrm{Sr}_{33} \mathrm{Ti}_{16} \mathrm{O}_{51}$ film with high permittivity and amorphous CoNbZr film was developed.

2. The permittivity of the deposited $\mathrm{Sr}_{33} \mathrm{Ti}_{16} \mathrm{O}_{51}$ film was estimated to be about 31 .

3. The sensor has good sensitivity of over 100 degree/Oe, and gain was within $-40 \mathrm{~dB}$ which is suitable for application to magnetocardiography (MCG).

4. The sensor with $\mathrm{Sr}_{33} \mathrm{Ti}_{16} \mathrm{O}_{51}$ film with high permittivity improved the sensitivity of magnetic field detection and exhibited reasonable gain compared with the sensor with $\mathrm{SiO}_{2}$ film with low permittivity.

\section{Acknowledgements}

This study was partly supported by a Grant-in-Aid for Scientific Research from Japan Society for the Promotion of Science. This study was partly supported by MEXT- Supported Program for the Strategic Research Foundation at Private Universities (20092013).

\section{References}

1) J.P. Wikswo, W.M. Fairbank, "Application of superconducting magnetoneters to the measurement of the vector magnetocardiogram," IEEE Trans. Magnetics, MAG13, pp. 354-357 (1977).

2) Y. Uchikawa, K. Sai, H. Ichikawa, K. Kobayashi, M. Kotani, "Three-Dimensional Measurement of MCG in a Normal Subject," Journal of the Magnetics Society of Japan, vol. 21, pp. 797-800 (1997).

3) S. Groeger, G. Bison, P. E. Knowles, R. Wynands, A. Weis, "Laser-pumped cesium magnetometers for high-resolution medical and fundamental research," Sensors and Actuators A, 129, pp. 1-5 (2006).

4) G. Baule, R. McFee, "Detection of the magnetic field of the heart," Am. Heart J, vol. 55, pp. 95-96 (1963).

5) C. Dolabdjian, S. Saez, A. Reyes Toledo, and D. Robbes," Signal-to-noise improvement of bio-magnetic signals using a flux-gate probe and real time signal processing," Review of Scientific Instruments, Vol. 69, No. 10, pp. 3678-3680 (1998).

6) K. Kojima, K. Sato, S. Yabukami, T. Ozawa, N. Kobayashi, and K. I. Arai "Sensitivity Enhancement of Transmissionline Thin-film Sensor by Using High-permittivity Substrate", Journal of the Magnetics Society of Japan, vol. 35, no. 3, pp. 277-280(2011).

7) S. Yabukami, K. Kato, T. Ozawa, N. Kobayashi, K. I. Arai, "A Measurement of Magnetocardiogram(MCG) in Multi Point Using a Transmission line type Thin-Film Sensor", IEEJ Transactions on Fundamentals and Materials, vol. 133, no.6, pp.372-375 (2013).

Received Sept. 27, 2013; Revised Feb. 12, 2013; Accepted Mar. 4,2013 